\title{
Directed migration of human neural progenitor cells to interleukin- $1 \beta$ is promoted by chemokines stromal cell-derived factor- 1 and monocyte chemotactic factor-1 in mouse brains
}

Yumei $\mathrm{Wu}^{1,3+}$, Qiang Chen ${ }^{1+}$, Hui Peng ${ }^{1}$, Huanyu Dou ${ }^{1}$, You Zhou ${ }^{4}$, Yunlong Huang ${ }^{1}$ and Jialin C Zheng ${ }^{1,2^{*}}$

\begin{abstract}
Background: Neurogenesis, including the proliferation, migration and differentiation of neural progenitor cells (NPCs), is impaired in HIV-1 associated dementia (HAD). We previously demonstrated HIV-1-infected macrophages (HIV-MDM) regulate stromal cell-derived factor 1 (SDF-1) production in astrocytes through Interleukin-1 $\beta$ (IL-1 $\beta$ ). Chemokines are known to induce NPC migration; however, it remains unclear how chemokines produced in inflammation regulate NPC migration.

Methods: The secretion of SDF-1 and Monocyte chemotactic preotein-1 (MCP-1) in astrocytes upon IL-1 $\beta$ stimulation was measured by ELISA assay. Human NPCs were injected parallel along with IL-1 $\beta$, SDF-1 or MCP-1 intracranially into basal ganglion $1 \mathrm{~mm}$ apart in SCID mice, and immunofluorescent staining was used to study the survival and migration of injected human NPCs.
\end{abstract}

Results: SDF-1 and MCP-1 are secreted by astrocytes upon IL-1 $\beta$ stimulation in a time-dependent manner. Injected human NPCs survived in SCID mice and migrated towards sites of IL-1 $\beta$, SDF-1 and MCP-1 injection.

Conclusions: In conclusion, chemokines SDF-1 or MCP-1 secreted by astrocytes in the presence of IL-1 $\beta$ injection are attractive to NPCs injected into SCID mouse brains, suggesting that SDF-1 and MCP-1 play important roles in NPC migration during neuroinflammation.

\section{Background}

HIV-associated dementia (HAD) is a progressive neurological disorder that affects $20 \sim 30 \%$ of patients with advanced HIV infection. Neurogenesis, which includes proliferation, migration and differentiation of neural progenitor cells (NPCs), in adults has been observed to be impaired in HAD patients [1]. The histological correlate of HAD is HIV-1 encephalitis (HIVE) which is characterized by reactive astrogliosis, accumulation of activated macrophages, microglial activation, virus-infected multinucleated giant cells, and neuronal damage [2]. Chemokines

\footnotetext{
* Correspondence: jzheng@unmc.edu

${ }^{\dagger}$ Equal contributors

${ }^{1}$ Department of Pharmacology and Experimental Neuroscience,

Neuroimmunology and Regenerative Therapy Laboratory, University of

Nebraska Medical Center, Omaha, Nebraska 68198, USA

${ }^{2}$ Department of Pathology and Microbiology, University of Nebraska Medical

Center, Omaha, Nebraska 68198, USA

Full list of author information is available at the end of the article
}

and chemokine receptors are up-regulated in the brains of patients with HIV and HIVE. Among these, stromal cellderived factor 1 (SDF-1) [3,4] and monocyte chemotactic protein-1 (MCP-1) [5,6] are documented to be involved in the pathogenesis of HAD. SDF-1, the ligand for CXCR4, has been shown to increase in patients with HIVE [3,4]. Evidence from knockout mouse studies showed that SDF-1 and its receptor CXCR4 are crucial for the nervous system development, especially in directing the migration of NPCs in the developing brain [7-10] and peripheral nervous system [11]. We previously found that SDF-1 increases in HAD patients in an IL-1 $\beta$-dependent manner [12]. Later studies supported that NPCs migrate to the ischemia region [13] and inflammatory area of the brain [14] in response to SDF-1 secretion.

Cells expressing CXCR4 frequently co-express CCR2 receptor on neurons and astrocytes in the cerebral cortex, hippocampus, and substantia nigra [15,16]. MCP-1, also 
named CCL2, is the ligand for chemokine receptor CCR2. Evidence has shown that MCP-1 is up-regulated [5] during HIVE and accumulates in the cerebrospinal fluid and brains of immunocompromised patients with HAD and HIVE. The HIV protein Tat elevates the expression of MCP-1 in astrocytes, while MCP-1 enhances virus replication and cell death, and can induce immune cells to migrate into the brain $[17,18]$. However, the exact role of MCP-1 in the development of $\mathrm{HAD}$ and especially how MCP-1 affects neurogenesis remains unclear. MCP-1 also plays a critical role in neuroblast migration after focal cerebral ischemia and induces migration and differentiation of subventricular zone cells after stroke [19], suggesting MCP-1 as a potential mediator for NPC migration under HIV-1 inflammation. Hypoxia-induced astrocytes promote the migration of NPCs via vascular endothelial growth factor, stem cell factor, SDF-1 and MCP-1 upregulation in vitro [14], further indicating that both SDF-1 and MCP-1 may play critical roles in NPC migration.

In order to achieve endogenous repair, the first step for NPCs is to migrate to regions of brain injury before differentiating into cells with the correct phenotype and then integrate appropriately into neuronal circuits [20]. However, our understanding as to how all of these processes occur during neurogenesis, and how they can be manipulated for therapeutic advantage is incomplete. NPCs provide precursor cells pools for adult neurogenesis for endogenous repair in the subventricular zone (SVZ) and subgranular zone (SGZ). Cell-replacement of NPCs for repairing brain damage in HAD is a subject of great interest $[21,22]$, holding out the hope of actually reversing neurodegeneration. Given the overview of neurogenesis, migration of NPCs is the critical step. To understand how and which chemokines affect NPC migration in HAD may provide possible ways to reverse HAD. However, the mechanism behind how HIVE inflammation induces NPC migration to repair damaged cells remains unclear. Our hypothesis is that chemokines, SDF-1, and MCP-1, produced by activated astrocytes in response to IL-1 $\beta$, promote NPC migration.

In this study, we investigated the migration of injected human NPCs in SCID mice brain by injecting human NPCs parallel to chemokines or cytokines. We found that chemokines, SDF-1, and MCP-1, were secreted by astrocytes time- and dose-dependently upon IL-1 $\beta$ stimulation, and human NPCs migrated to SDF-1 and MCP-1 in the SCID mouse model. Our data provide further evidence for the critical roles of SDF-1 and MCP-1 in mediating NPC migration during brain inflammation, thus affecting neurogenesis.

\section{Methods}

Reagents and materials

Human recombinant SDF-1 and MCP-1 were obtained from R \& D Systems (Minneapolis, MN). X-Vivo 15 and neural cell survival factor-1 (NSF-1) were purchased from Lonza (Basel, Switzerland). Fetal bovine serum and $\mathrm{N}_{2}$ supplement were from Life Technologies (Carlsbad, CA). $\mathrm{N}$-acetylcysteine, basic fibroblast growth factor (bFGF) and epidermal growth factor (EGF) were obtained from Sigma-Aldrich (St. Louis, MO). Leukemia inhibitory factor (LIF) was purchased from Chemicon (Temecula, CA). Anti-Nestin and anti-GFAPantibodies were purchased from Cell Signaling (Cell Signaling, Danvers, MA). All secondary antibodies and Qtracker565 Cell Labeling Kit were purchased from Life Technologies (Carlsbad, CA).

\section{Human fetal NPC and astrocyte culture}

Human NPCs and astrocytes were isolated from human fetal brain tissue (gestational age 13-16 weeks) from elective aborted specimens in full compliance with University of Nebraska Medical Center and NIH ethical guidelines as previously described [10]. Briefly, NPCs were cultured in substrate-free tissue culture flasks and grown as neurospheres in neurosphere initiation medium (NPIM), which consisted of X-Vivo 15 with N2 supplement, NSF-1, bFGF, (20 ng/ml), EGF (20 ng/ml), LIF (10 ng/ml), and N-acetylcysteine (60 ng/ml). Cells were passaged at two-week intervals as previously described [10]. Human astrocytes were cultured at a density of $2 \times 10^{7}$ cells/150 $\mathrm{cm}^{2}$ in DMEM/F12 (Life Technologies, Carlsbad, CA), supplemented with FBS (10\%), and an antibiotic mixture containing penicillin, streptomycin, and neomycin (Life Technologies, Calsbad, CA). The adherent astrocytes were passaged by treating with $0.25 \%$ trypsin (Life Technologies, Calsbad, CA) after 2 weeks in culture to enhance purity. Astrocyte preparations were assessed by immunocytochemical staining using antibody for GFAP. This process yielded a culture of $>98 \%$ pure astrocytes.

\section{Transwell chemotaxis assay}

NPC migration was evaluated using an $8-\mu \mathrm{m}$ pore size transwell system (Costar, Cambridge, MA) precoated with fibronectin (Sigma-Aldirich, St. Louis, MO) at $5 \mathrm{ng} / \mathrm{ml}$ in PBS overnight. Briefly, NPCs were dissociated into single cells and resuspended in X-Vivo 15 at a density of $10^{6}$ cells $/ \mathrm{ml}$. The top chamber of the transwell was loaded with $100 \mu \mathrm{l}$ of cell suspension and cells were cultured for 12 hours to form an adherent monolayer culture. SDF-1 or MCP-1 was added to the bottom chamber as described concentration in X-Vivo 15. After 12 hours, the membrane of the transwell insert was fixed with 4\% PFA in PBS, and cells on top of the membrane were removed with a cotton swab. Cells that migrated to the bottom of the membrane were stained with DAPI (Sigma-Aldrich, St Luis, MO) in PBS at $10 \mathrm{ng} / \mathrm{ml}$. For each insert 10 fields were randomly selected under microscopy at $20 \times$ for imaging, and cell numbers were 
counted by Image-Pro Plus 7.0 (MediaCybernetics, Bethesda, MD). The cell number of each treated group was normalized to the cell number of the control group to calculate the migration index. Statistical differences were assessed by student $t$-test $(p<0.05)$.

\section{ELISA assay}

To assess the concentrations of secreted SDF-1 and MCP-1 in supernatants of astrocytes upon IL-1 $\beta$ stimulation, we used a sandwich fluorescence ELISA system with modifications to a previously described assay [12,23] for SDF-1 and MCP-1 measurement. In brief, 96-well microtiter plates (Corning, Corning, NY) were coated overnight at room temperature with mouse antiSDF-1 and anti-MCP-1 monoclonal antibody $(4 \mu \mathrm{g} / \mathrm{ml}$, R \& D Systems, Minneapolis, MN) in PBS. Non-specific binding was blocked for $2 \mathrm{~h}$ with $1 \%$ BSA in PBS. Triplicate samples of cell supernatant $(100 \mu \mathrm{l})$ or a serial dilution of standards of human recombinant SDF-1 and MCP-1 ( R \& D Systems, Minneapolis, MN)were applied to the wells and incubated overnight at $4^{\circ} \mathrm{C}$. Samples were then incubated for $1 \mathrm{~h}$ at room temperature with the biotinylated goat anti-SDF-1 and anti-MCP-1 antibodies $(300 \mathrm{ng} / \mathrm{ml}$ ), followed by $1 \mathrm{~h}$ incubation with HRP-conjugated streptavidin ( R \& D Systems, Minneapolis, MN). After three washes with PBS containing 0.05\% Tween 20 (PBST), the final reaction product was detected using QuantaBlu ${ }^{\mathrm{Tm}}$ Fluorogenic Peroxidase Substrate (Pierce, Rockford, IL). Plates were read by SpectraMax GEMINI (325 nm excitation, $420 \mathrm{~nm}$ emission, Molecular Devices, Sunnyvale, California). The sensitivity for this assay was $100 \mathrm{pg} / \mathrm{ml}$ for SDF-1. For MCP-1 detection,a chromogen substrate K-bluewas then added at room temperature for color development, and stopped with $1 \mathrm{M} \mathrm{H}_{2} \mathrm{SO}_{4}$. The plate was read at $450 \mathrm{~nm}$ to generate standard concentration curves for $\mathrm{MCP}-1$ concentration extrapolation.

\section{Human NPC and cytokine/chemokines parallel injections in SCID mice}

Four-week-old male C.B.-17 SCID mice were purchased from the Charles River Laboratory. All mice were housed in the animal facilities at the University of Nebraska Medical Center. All procedures were conducted according to protocols approved by the Institutional Animal Care and Use Committee (IACUC) of the University of Nebraska Medical Center. Briefly, mice were anesthetized with Ketamine $(120 \mathrm{mg} / \mathrm{kg}$ ) and xylazine (16 $\mathrm{mg} / \mathrm{kg}$ ) by i.p, placed in a stereotaxic apparatus (Stoetling, Wood Dale, IL) for intracranial injection in the right cerebral hemisphere. The animal's head was secured with ear bars and mouthpiece. An injector with a 10- $\mu$ l syringe was used for cell injection. NPCs at passage 6-9 were labeled with Qtracker565 Cell Labeling
Kit and injected into SCID mice at one site, with IL-1 $\beta$ /SDF-1/MCP-1 (25 ng in $2.5 \mu \mathrm{l}$ ) injected at the other site $1 \mathrm{~mm}$ apart from the NPC injection siteinto the basal ganglion of SCID mice, PBS was used as control. Coordinates for inoculation were set as: $0.5-0.8 \mathrm{~mm}$ posterior to Bregma, $3.5 \mathrm{~mm}$ lateral form the Sagittal midline, a depth and angle of $3.6 \mathrm{~mm}$ and $35^{\circ}$ from the vertical line. Mice were sacrificed 7 days after injection and brains were immediately removed and then placed in 4\% PFA for postfixation. The distance between two injection sites was dived into 5 even sections ( $2 \mu \mathrm{m}$ each section). A confocal image was taken for each section.

\section{Immunocytochemistry}

Immunocytochemistry for the detection of NPC was performed as described previously [10]. Briefly, cells were fixed with methanol/acetone (1:1) and then washed with PBS. Cells were incubated with antibody for Nestin (1:100; Sigma-Aldrich, St. Louis, Missouri) overnight and then followed by incubation with goat anti-mouse IgG Alexa Fluor 488 (1:1000). Hoechst 33342 (1:5,000, Sigma-Aldrich, St. Louis, Missouri) was used for nuclear staining. Double immunostaining was examined by an E800 Eclipse microscope (Nikon, Japan). For brain tissue

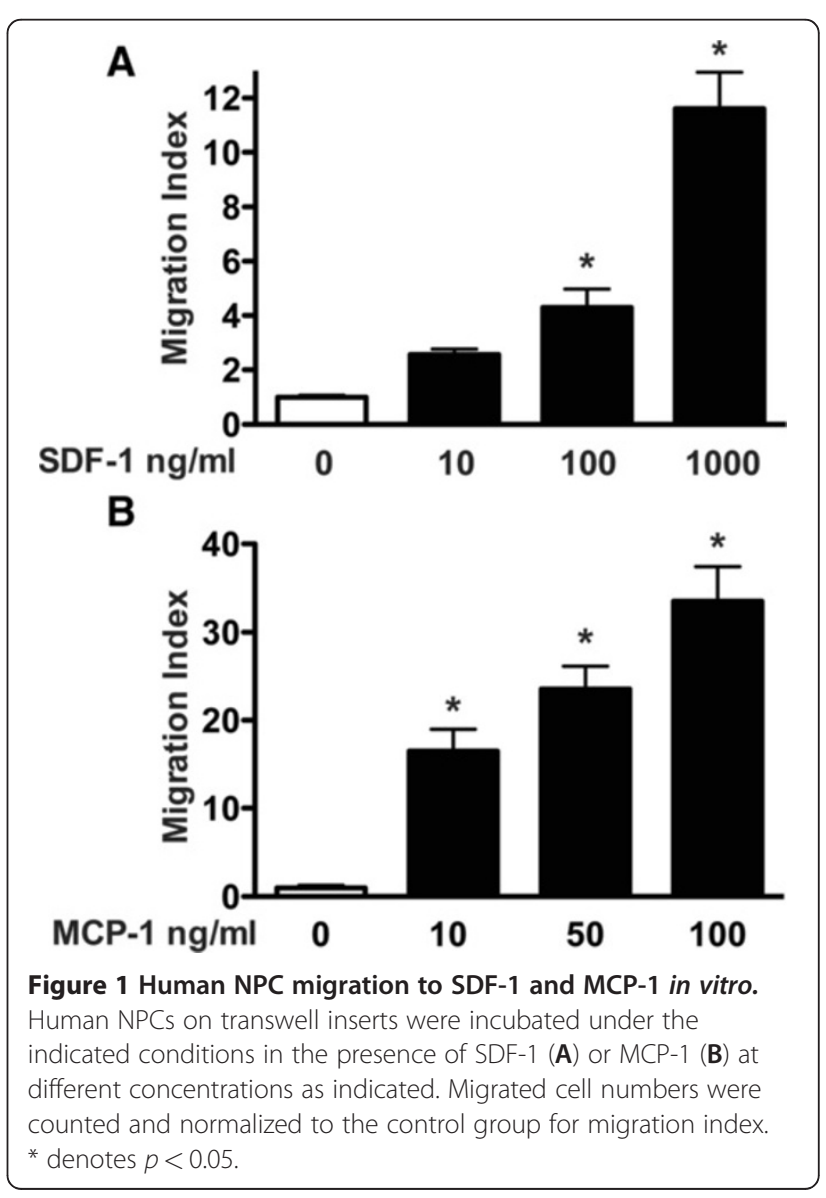


staining, $30 \mu \mathrm{m}$-thick sections were permeabilized by 0.3\% Triton X-100 (Sigma-Aldrich, St. Louis, Missouri) in PBS for $1 \mathrm{~h}$ at room temperature, and then blocked in $10 \%$ goat serum for at least $1 \mathrm{~h}$ at room temperature. Sections were incubated overnight with anti-GFAP and anti-Nestin antibodies at $4^{\circ} \mathrm{C}$ overnight with shaking, followed with goat anti-mouse and anti-rabbit IgG Alexa Fluor 488 or 594, and donkey anti-rabbit IgG Alexa Fluor 647 (1:1000) for $1 \mathrm{~h}$ at room temperature.

\section{Confocal examination and image analyses}

For fluorescence evaluation of human NPC migration to PBS/IL-1 $\beta /$ SDF-1/MCP-1 injection site, brain tissue was collected on post-treatment day 3 after perfusion fixation with $4 \%$ paraformaldehyde in PBS. Immunofluorescent staining was performed on sucrose-processed $30-\mu \mathrm{m}$ frozen brain sections. Antibody for human specific Nestin (AB5922, Millipore, Billerucam, MA ) was used for detection of human NPC in the mouse brain. Astrocytes detected with antibody for GFAP were also observed to display two injection lines. NPC migration patterns (distance and percentage) were visualized and captured with an Olympus FV500 confocal laser scanning microscope using sequential 488/568/647 nm laser line excitation respectively, and images were imported into ImageProPlus for quantification. NPC migration distance was determined as the distance between the NPC injection site and the furthest NPC migrating in each slice. At least 500 total Nestin positive cells in each section and five serial slides $(30-\mu \mathrm{m}$ slide) were measured. The migration distance was divided into five even sections and serial confocal images were captured. NPCs in each part were counted and the percentage of the migrating NPCs in each part was calculated as the percentage of the cells in each part to the total number of injected cells (human NPCs).
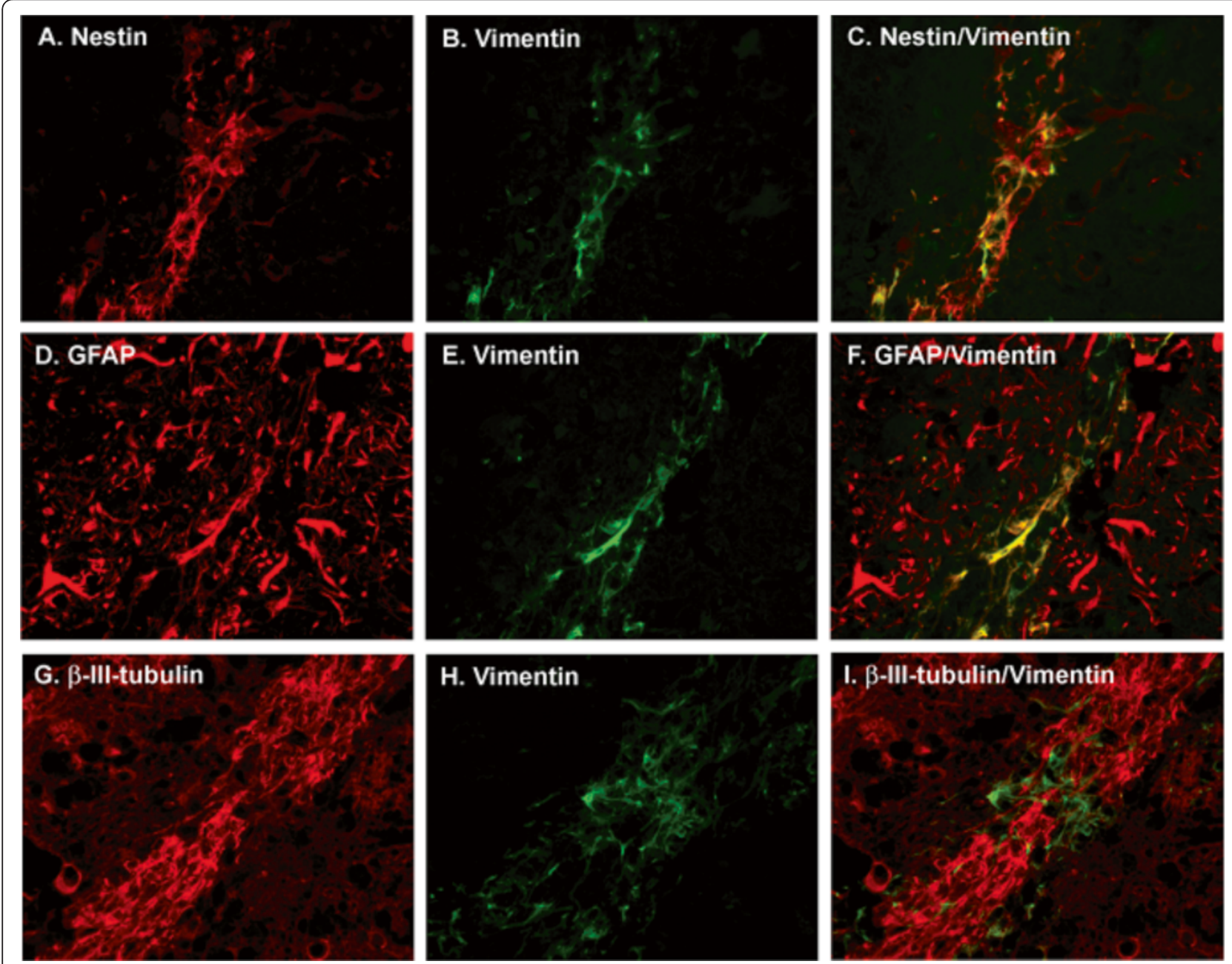

Figure 2 Human NPC survival and differentiation in SCID mice brain. Higher magnification (60X) pictures showed injected NPCs expressed Nestin (A), weak GFAP (D) and Vimentin (B, E and $\mathbf{H}$ ). Neuronal differentiated cells ( $\beta$-III-tubulin/vimentinpositive) shown in $\mathrm{G}$ did not integrate into the tissue. 


\section{Statistical tests}

All results were expressed as means \pm standard deviation of the mean (SD) or standard error of the mean (SEM). All experiments were done in triplicate or quadruplicate. Data was evaluated statistically by student $t$-test and analysis of variance (ANOVA). Significance was considered to be $p$ less than 0.05 . To account for any donor specific differences, all experiments were performed with a minimum of three donors.

\section{Results}

SDF-1 and MCP-1 promote human NPC migration in vitro

We first studied the role of the chemokines SDF-1 and MCP-1 in NPC migration using transwell chemotaxis assay in vitro. Both SDF-1 and MCP-1 promoted human NPC migration in vitro in a dose-dependent manner (Figure 1) as compared to the negative control (basal culture media X-Vivo 15 without chemokine). SDF-1 significantly promoted human NPC migration starting at $100 \mathrm{ng} / \mathrm{ml}$, and MCP-1 significantly promoted human $\mathrm{NPC}$ migration starting at $50 \mathrm{ng} / \mathrm{ml}$. With the expression of both chemokine receptors CXCR4 and CCR2 in human NPC [13,24], the in vitro data suggested that chemokines SDF-1 and MCP-1 promote NPC migration in vitro.

\section{Human NPC survival and differentiation in SCID mice brain}

NPCs provide a reservoir to replace neurons or glia during conditions of brain injury or disease, and therefore have potential for transplantation therapies in neurodegenerative diseases. To achieve this aim, injected/transplanted NPCs must be able to survive and and differentiate into cells of the correct phenotype. Before determining whether chemokines, SDF-1 and MCP-1, promote NPC migration in SCID mouse brains, we need to study whether injected NPCs can survive and differentiate into proper cell types. We used $5 \mu \mathrm{m}$-thick paraffin brain sections to check the survival and differentiation of injected cells by immunostaining with antibodies for NPC marker Nestin and differentiation markers for both neurons and astrocytes, together with human species-specific antibody for Vimentin (a marker for NPC and radial glia) to show the injected human NPC [25]. Figure 2A, B, and C showed that human NPC survived and expressed the NPC markers Nestin and Vimentin, and Figure 2D to I showed NPCs differentiated into astrocytes and neurons, with the expression of NPC specific marker Vimentin to show the human NPC injection site (Figure 2E and $\mathrm{H}$ ). The integration of NPC and differentiated cells into the host tissue was not observed probably due to the limitation of length of injection time. Higher magnification pictures showed injected NPC expressed Nestin (Figure 2A), weak GFAP (Figure 2D), $\beta$-III-tubulin and Vimentin (Figures 2B, E and $\mathrm{H})$. Neuronal differentiated cells ( $\beta$-III-tubulin) shown in Figure $2 \mathrm{G}$ did not integrate into the tissue. These results show that human NPCs survived and differentiated into neurons and astrocytes after injection into the SCID mouse brain.

The production of SDF-1 and MCP-1 in human astrocytes is stimulated by IL-1 $\beta$

Our laboratory previously reported that astrocytes are the major cell type in the brain that is responsible for SDF-1 production and regulation during HIV-1 infection [12]. MCP-1 is another important chemokine that induces immuno-cell migration during inflammation [26]. To investigate the role of SDF-1 and MCP-1 in mediating NPC migration to IL-1 $\beta$ stimulation, we reasoned that both SDF-1 and MCP-1 released by astrocytes upon IL-1 $\beta$ stimulation are the major attractants for NPC migration in diseased brain or during
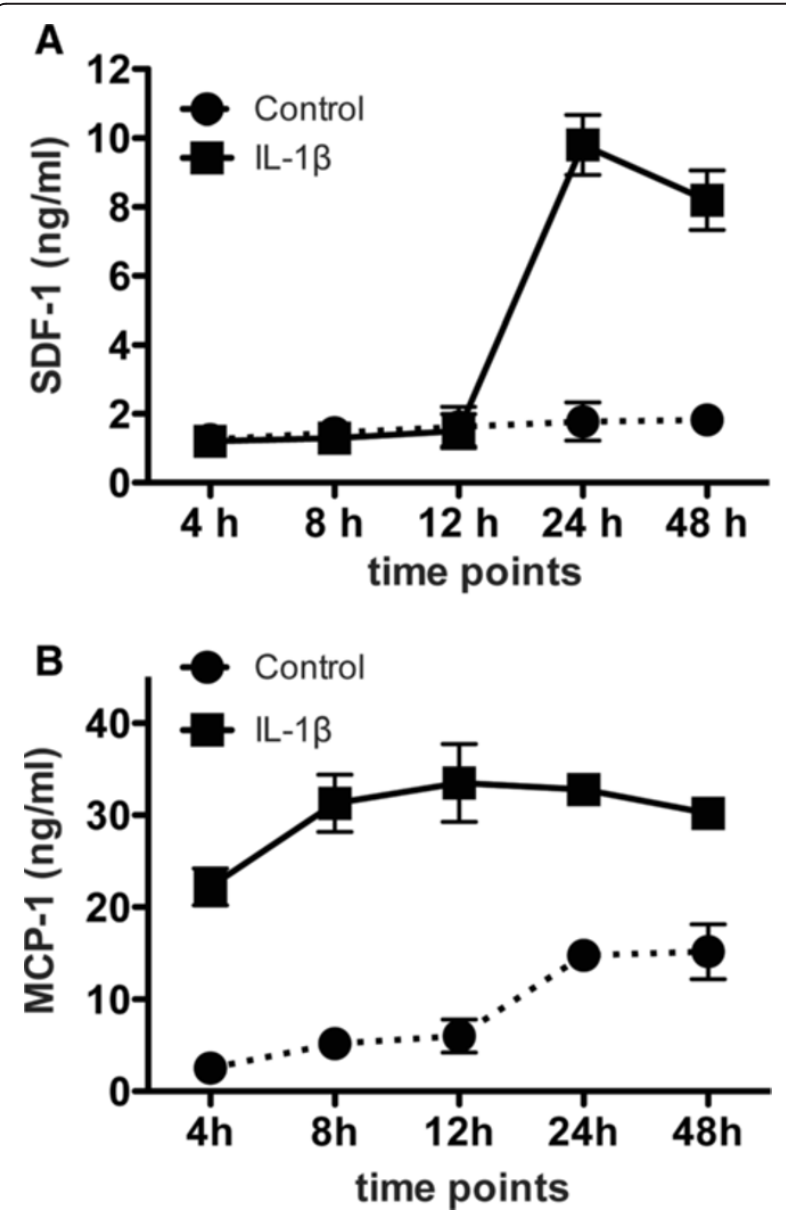

Figure 3 The production of SDF-1 and MCP-1 in human astrocytes stimulated with IL-1 $\beta$. Human astrocytes were stimulated with IL-1 1 (500 $\mathrm{ng} / \mathrm{ml})$, and supernatant was collected at different time points and subjected to ELISA assay. Both of SDF-1 (A) and MCP-1 (B) showed time-dependent increase upon IL-1 $\beta$ stimulation in astrocytes with a peak time around 24 hour. 


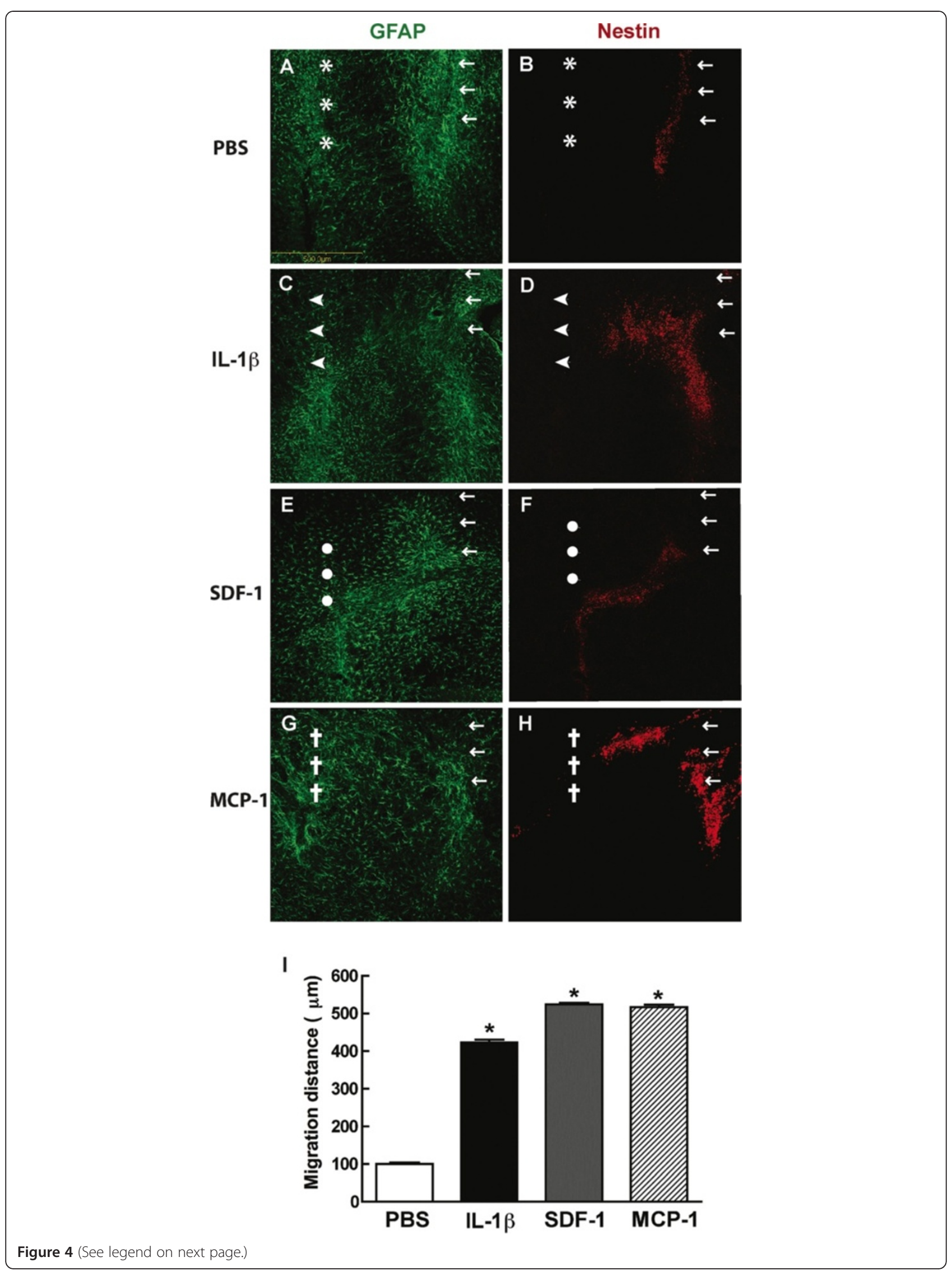


brain inflammation. Since astrocytes are the most abundant cells in the brain and response under cytokine stimulation, it is important to study the release of both chemokines by astrocytes upon IL-1 $\beta$ treatment in vitro. Human astrocytes were stimulated with IL-1 $\beta(500 \mathrm{ng} / \mathrm{ml})$ at different time points and supernatant was collected and subjected to ELISA assay. Both SDF-1 (Figure 3A) and MCP-1 (Figure 3B) showed time-dependent increase upon IL-1 $\beta$ stimulation in astrocytes with peak time around 24 hour.

\section{Migration patterns of human NPC after injection along with IL-1 $\beta /$ SDF-1/MCP-1}

Injecting/transplanting human cells in a mouse model allows us to track NPC migration, survival, proliferation and differentiation properties in vivo. However, antibodies for $\beta$-III-tubulin and GFAP are not species-specific. We overcame this obstacle by labeling human NPC with Qtracker565 Cell Labeling Kit to differentiate transplanted human cells from host mouse cells. In the present study, human NPCs were injected into basal gangalia of SCID mice, and $1 \mathrm{~mm}$ apart from the NPC injection site, PBS $(2.5 \mu \mathrm{l}), \mathrm{IL}-1 \beta$, SDF-1 or MCP-1 (25 ng in $2.5 \mu \mathrm{l})$ were parallelly injected ( $n=3$ per group). The injection sites were indicated by GFAP (Figure 4A, C, E and G, $10 \times$ ) and injected human NPCs were visualized by human Nestin (Figure 4B, D, F and H, $10 \times$ ). Confocal images illustrated NPC migrated towards the IL-1 $\beta$ (Figure 4D) injection site as well as SDF-1 (Figure 4F) and MCP-1 (Figure 4H) injection sites, whereas fewer NPCs migrated towards the PBS injection site (Figure 4B). The migration distance was determined as the distance between the furthest migrated NPCs and the NPC injection line, as showed in Figure 4I. NPC migration distance was determined with at least 500 total Nestin positive cells in each section of five serial sections (30 $\mu \mathrm{m} /$ section).

\section{Percentage of human NPC migration induced by IL-1 $\beta$}

IL- $1 \beta$ is an identified factor by which SDF-1 production is modulated in vivo. In order to obtain the details about the migration of NPCs induced by IL-1 $\beta$, SDF-1, or MCP-1, NPC and PBS, IL- $1 \beta$, SDF-1 or MCP-1 were injected $1 \mathrm{~mm}$ apart into the basal ganglion of SCID mice. The distance between the two injection sites was divided into 5 even sections as diagramed in Figure 5E. Nestin positive cells (red) in each part were counted, and the percentage of the migrating NPCs in each part were calculated as the cells in each part/ total migrated cells counted. $83.8 \%$ NPCs in PBS group were mainly distributed around the injection site (Figure 5A1, A2 and $\mathrm{F}$ ), and no cells were found beyond the second section (Figure 5 A3, A4, A5 and F), suggesting that NPCs mainly stayed in the original injection site, with few cells migrating out of the injection site. The astrogliosis induced by PBS injection was not strong enough to mediate NPC migration. Meanwhile, IL-1 $\beta$ injection led to severe astrogliosis and NPCs migrated further towards IL-1 $\beta$ injection site (Figure 5B1-B5), and 32.8\%, 32.4\%, $23 \%, 6.7 \%$ and $5.1 \%$ cells migrated to IL- $1 \beta$ injection sites in each part (Figure $5 \mathrm{~F}$ ). This suggests IL-1 $\beta$ mediates NPC migration in SCID mice.

\section{Percentage of human NPC migration induced by SDF-1 and MCP-1}

Based on the observation that SDF-1 and MCP-1 produced by astrocytes upon IL- $1 \beta$ stimulation and both chemokines mediated NPC migration, we investigated the difference of the NPC migration induced by SDF-1 and MCP-1. We then injected NPC and SDF-1 or MCP$1,1 \mathrm{~mm}$ apart into the basal ganglion of SCID mice. More NPC migration induced by both chemokines was observed compared with the PBS injection control. The distance between the two injection sites was divided into five even sections as diagramed in Figure 5E. NPCs migrated further towards SDF-1 (Figure 5C1-C5) and MCP-1 (Figure 5D1-D5) injection sites as compared to the PBS injection. $25.4 \%, 16.2 \%, 35.6 \%, 20.2 \%$ and $2.5 \%$ NPC migrated towards SDF-1 injection sites in each part (Figure 5G), and 40.8\%, 25.8\%, 12.9\%, 12.4\% and $8.1 \%$ cells migrated towards MCP-1 (Figure $5 \mathrm{H}$ ) injection site in each part.

\section{Discussion}

In this study, we observed that injected/transplanted NPCs survived and differentiated in SCID mouse brains, and migrated towards the IL- $1 \beta$ injection site and that this may be due to the release of chemokines, SDF-1 and MCP-1 from activated astrocytes which are involved in the pathology upon CNS inflammation induced by IL-1 $\beta$. To our knowledge, this is the first report to show that the injected human NPCs migrate towards an IL-1 $\beta$ injection site in vivo, and that IL-1 $\beta$ may influence neurogenesis during CNS inflammation and disease in brains, and chemokines SDF-1 and MCP-1 released 


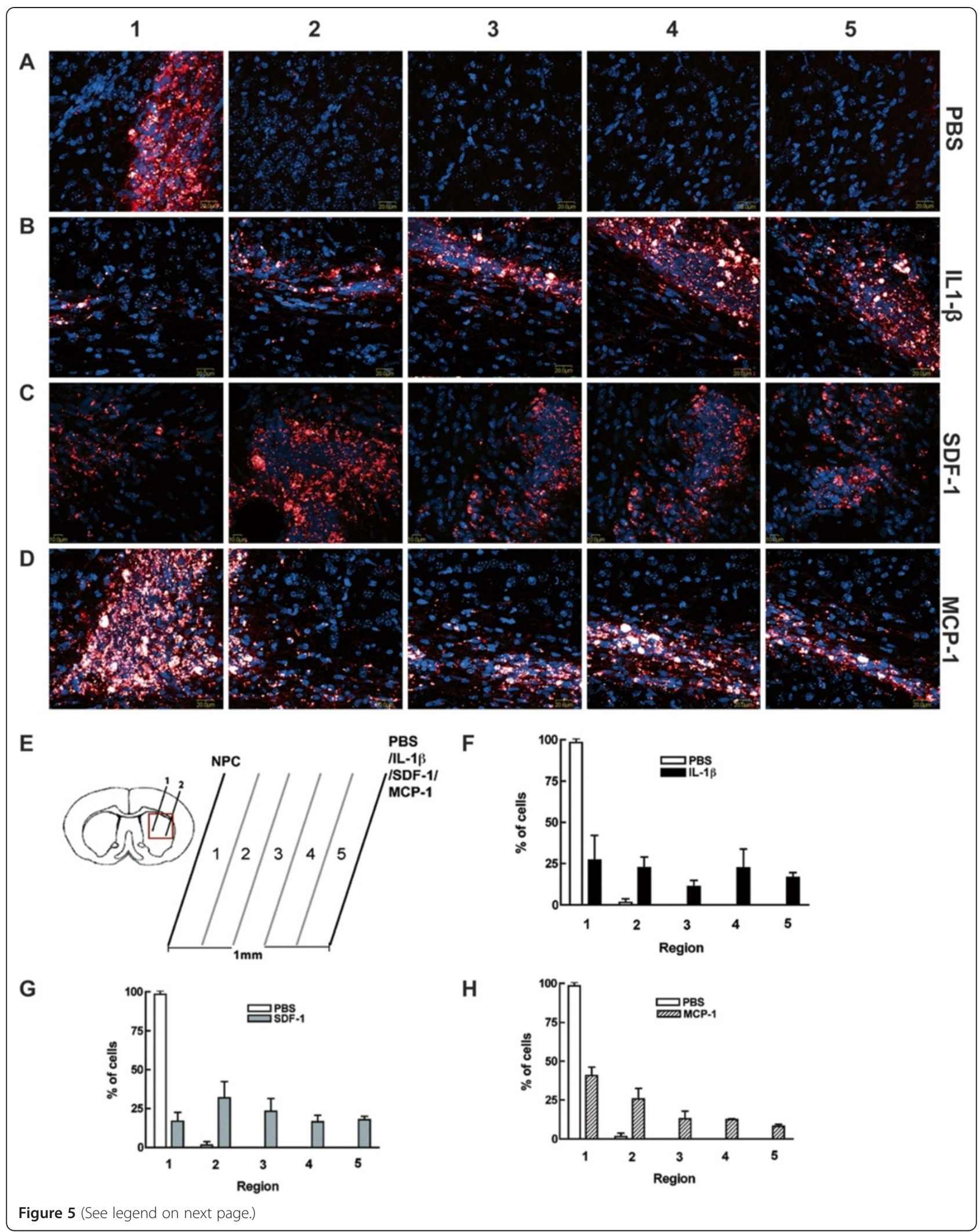


from activated astrocytes are the main factorsponsible for this process.

It is now accepted that neurogenesis takes place throughout life and is capable of replacing neurons, astrocytes, and oligodendrocytes under conditions of brain injury or disease [27-29]. Notably, neurogenesis is indicated to be impaired during brain injury and neurodegenerative disorders by the dysregulation of cytokines, chemokines, neurotransmitters, and reactive oxygen species caused by inflammation and mediated by activated macrophages, microglia and reactive astrocytes [2]. Endogenous neural stem cells produce new neurons to repair in response to injury $[22,30,31]$; however, neurogenesis has been observed to be diminished in HAD $[12,32]$. Up to now, our understanding as how all these process occurs, and how neurogenesis can be manipulated towards therapeutic advantages is incomplete.

Chemokines orchestrate the immune system and as well play important roles in activating and recruiting different types of brain cells to a region of injury associated with the pathogenesis of inflammatory neurodegenerative disease [33-36]. The chemokine receptors CCR2, CCR5, CXCR2, CXCR3, CXCR4 and CX3CR1 are constitutively expressed in the human brain, and their expression is enhanced under pathological conditions, including stroke $[13,24]$ and neurodegenerative diseases like HIV-associated dementia (HAD) $[4,37]$ and Alzheimer's disease (AD) [38]. It is very clear that NPCs express diverse chemokine receptors $[39,40]$ and the NPC migration is promoted by chemokines [41]. To study the role of SDF- 1 and MCP-1 in the neurogenesis during CNS inflammation induced by $\mathrm{IL}-1 \beta$, we determined the expression levels of two receptors for both chemokines in NPCs. Our data showed that human NPCs highly expressed CXCR4 and CCR2 by FACS and immuno-staining (data not shown), and this observation kept consistence with previous reports $[10,26]$. NPC migration towards a single destination is a rapid process and is the essential step not only for the brain development, but also for the pathological mechanisms responsible for CNS disorders [8].

Our laboratory previously demonstrated that SDF-1 secretion from astrocyte stimulated with conditional media from HIV-MDM is through IL-1 $\beta$, indicating that SDF-1 /CXCR4 signaling is important for HIVE pathogenesis
[12]. Since CNS inflammation and encephalit is during HIV-1 infection have been shown to decrease neurogenesis, it is possible that deficits of neurogenesis occur in HAD. Taking into consideration that NPCs clearly express diverse chemokine receptors including CXCR4 and CCR2, what are the important roles of chemokines during the progress of HAD? Elucidating the molecular mechanisms that mediate chemokine-induced neurogenesis could facilitate the use of NPCs to replenish neurons for therapeutic transplantation in CNS diseases.

SDF-1/CXCR4 have been shown to be the most important chemokine and chemokine receptor in the CNS development and mediating NPC migration in adults [7-10]. We previously found that SDF-1 increased in HAD patients in an IL-1 $\beta$-dependent manner [12], so how does this chemokine and its receptor affect NPC migration in the HAD and other brain inflammatory diseases? We have showed that IL- $1 \beta$, the brain inflammation model we applied, stimulated the production of SDF-1, and both IL-1 $\beta$ and SDF-1 can induce NPC migration. We conclude that SDF-1 is a chemokine that is involved in the impairment of neurogenensis.

We adapted a brain inflammation model with IL-1 $\beta$ injection and determined that IL- $1 \beta$ mediated NPC migration through chemokines SDF-1 and MCP-1. First we observed that injected/transplanted human NPCs survived and differentiated in SCID mouse models with or without cytokine/chemokines injection. This is the basis for a therapeutic purpose of NPC transplantation. We also found that NPCs migrating to IL- $1 \beta$ may through chemokines SDF-1 and MCP-1. It has been demonstrated by our laboratory that SDF-1 secretion from astrocytes mediated by HIV-MDM is through IL- $1 \beta$, indicating that SDF-1/CXCR4 signaling is important for HIVE pathogenesis [12].

\section{Conclusions}

In this study, we investigated the potential role of IL- $1 \beta$ in inducing NPC migration by stimulating SDF-1 and MCP-1 production by astrocytes, and, together we showed that injected human NPC survived and differentiated into astrocytes and neurons in SCID mice brains. This has shed light on the pathological process of HAD. Our finding of NPC migration to inflammatory cytokine 
IL-1 $\beta$ also suggests the potential therapeutic application of NPC transplantation in neurodegenerative diseases.

\section{Competing interests}

The authors declare that they have no competing interest.

\section{Authors' contributions}

Conceived and designed the experiments: YW QC HP YH JCZ. Performed the experiments: YW QC HP HD YZ YH. Analyzed the data: YW YZ YH. Contributed reagents/materials/analysis tools: YZ JZ. Wrote the paper:YW QC HP HD YZ YH JCZ. All authors read and approved the final manuscript.

\section{Acknowledgements}

This work was supported in part by research grants by the National Institutes of Health: R01 NS 41858-01, R01 NS 061642-01, R01NS61642-2 S1, R21 MH 083525-01, P01 NS043985, and P20 RR15635-01 to JZ, and National Natural Science Foundation of China (NSFC) \# 81028007 to JZ, \# 81101457 to YW, and Scientific Research Foundation for the Returned Overseas Chinese Scholars No.HG3402 to YW. We kindly acknowledge Dr. Changhai Tian, Li Wu, and Dr. Jim Eudy (UNMC microarray core facility). Kristin Leland Wavrin provided valuable comments and suggestions about the manuscript. Dr. Charles Kuszynski and Linda Wilkie performed the FACS analysis. Julie Ditter, Robin Taylor, Myhanh Che, Na Ly, and Emilie Scoggins provided outstanding administrativesupport.

\section{Author details}

${ }^{1}$ Department of Pharmacology and Experimental Neuroscience, Neuroimmunology and Regenerative Therapy Laboratory, University of Nebraska Medical Center, Omaha, Nebraska 68198, USA. ${ }^{2}$ Department of Pathology and Microbiology, University of Nebraska Medical Center, Omaha, Nebraska 68198, USA. ${ }^{3}$ Department of Pharmacology, School of Pharmacy, The Fourth Military Medical University, Xi'an, Shaanxi 710032, People's Republic of China. ${ }^{4}$ Center for Biotechnology, University of Nebraska Lincoln, Lincoln, Nebraska 68588, USA.

Received: 9 June 2012 Accepted: 15 July 2012

Published: 31 July 2012

\section{References}

1. Okamoto S, Kang YJ, Brechtel CW, Siviglia E, Russo R, Clemente A, Harrop A, McKercher S, Kaul M, Lipton SA: HIV/gp120 decreases adult neural progenitor cell proliferation via checkpoint kinase-mediated cell-cycle withdrawal and G1 arrest. Cell Stem Cell 2007, 1:230-236.

2. Avgeropoulos NG, Burris GW, Ohlandt GW, Wesselingh SL, Markham RB, Tyor WR: Potential relationships between the presence of HIV, macrophages, and astrogliosis in SCID mice with HIV encephalitis. J NeuroAIDS 1998, 2:1-20

3. Langford D, Sanders VJ, Mallory M, Kaul M, Masliah E: Expression of stromal cell-derived factor 1alpha protein in HIV encephalitis. J Neuroimmunol 2002, 127:115-126.

4. Rostasy K, Egles C, Chauhan A, Kneissl M, Bahrani P, Yiannoutsos C, Hunter DD, Nath A, Hedreen JC, Navia BA: SDF-1alpha is expressed in astrocytes and neurons in the AIDS dementia complex: an in vivo and in vitro study. J Neuropathol Exp Neurol 2003, 62:617-626.

5. Cinque $P$, Vago L, Mengozzi M, Torri V, Ceresa D, Vicenzi E, Transidico $P$, Vagani A, Sozzani S, Mantovani A, et al: Elevated cerebrospinal fluid levels of monocyte chemotactic protein-1 correlate with HIV-1 encephalitis and local viral replication. AIDS 1998, 12:1327-1332.

6. Conant K, Garzino-Demo A, Nath A, McArthur JC, Halliday W, Power C, Gallo RC, Major EO: Induction of monocyte chemoattractant protein-1 in HIV-1 Tat-stimulated astrocytes and elevation in AIDS dementia. Proc Natl Acad Sci USA 1998, 95:3117-3121.

7. Lu M, Grove EA, Miller RJ: Abnormal development of the hippocampal dentate gyrus in mice lacking the CXCR4 chemokine receptor. Proc Natl Acad Sci U S A 2002, 99:7090-7095.

8. Zou YR, Kottmann AH, Kuroda M, Taniuchi I, Littman DR: Function of the chemokine receptor CXCR4 in haematopoiesis and in cerebellar development. Nature 1998, 393:595-599.

9. Ma Q, Jones D, Borghesani PR, Segal RA, Nagasawa T, Kishimoto T, Bronson RT, Springer TA: Impaired B-lymphopoiesis, myelopoiesis, and derailed cerebellar neuron migration in CXCR4- and SDF-1-deficient mice. Proc Natl Acad Sci U S A 1998, 95:9448-9453.

10. Peng H, Huang Y, Rose J, Erichsen D, Herek S, Fujii N, Tamamura H, Zheng J: Stromal cell-derived factor 1-mediated CXCR4 signaling in rat and human cortical neural progenitor cells. J Neurosci Res 2004, 76:35-50.

11. Belmadani A, Tran PB, Ren D, Assimacopoulos S, Grove EA, Miller RJ: The chemokine stromal cell-derived factor-1 regulates the migration of sensory neuron progenitors. The Journal of neuroscience: the official journal of the Society for Neuroscience 2005, 25:3995-4003.

12. Peng H, Erdmann N, Whitney N, Dou H, Gorantla S, Gendelman HE, Ghorpade A, Zheng J: HIV-1-infected and/or immune activated macrophages regulate astrocyte SDF-1 production through IL-1beta. Glia 2006, 54:619-629.

13. Robin AM, Zhang ZG, Wang L, Zhang RL, Katakowski M, Zhang L, Wang $Y$, Zhang C, Chopp M: Stromal cell-derived factor 1alpha mediates neural progenitor cell motility after focal cerebral ischemia. Journal of cerebral blood flow and metabolism: official journal of the International Society of Cerebral Blood Flow and Metabolism 2006, 26:125-134.

14. Xu Q, Wang S, Jiang X, Zhao Y, Gao M, Zhang Y, Wang X, Tano K, Kanehara $M$, Zhang W, Ishida T: Hypoxia-induced astrocytes promote the migration of neural progenitor cells via vascular endothelial factor, stem cell factor, stromal-derived factor-1alpha and monocyte chemoattractant protein-1 upregulation in vitro. Clin Exp Pharmacol Physiol 2007, 34:624-631.

15. van der Meer P, Ulrich AM, Gonzalez-Scarano F, Lavi E: Immunohistochemical analysis of CCR2, CCR3, CCR5, and CXCR4 in the human brain: potential mechanisms for HIV dementia. Exp Mol Pathol 2000, 69:192-201.

16. Coughlan CM, McManus CM, Sharron M, Gao Z, Murphy D, Jaffer S, Choe W, Chen W, Hesselgesser J, Gaylord $\mathrm{H}$, et al: Expression of multiple functional chemokine receptors and monocyte chemoattractant protein-1 in human neurons. Neuroscience 2000, 97:591-600.

17. Babcock AA, Kuziel WA, Rivest S, Owens T: Chemokine expression by glial cells directs leukocytes to sites of axonal injury in the CNS. J Neurosci 2003, 23:7922-7930

18. Widera D, Holtkamp W, Entschladen F, Niggemann B, Zanker K, Kaltschmidt B, Kaltschmidt C: MCP-1 induces migration of adult neural stem cells. Eur J Cell Biol 2004, 83:381-387.

19. Yan YP, Sailor KA, Lang BT, Park SW, Vemuganti R, Dempsey RJ: Monocyte chemoattractant protein-1 plays a critical role in neuroblast migration after focal cerebral ischemia. J Cereb Blood Flow Metab 2007, 27:1213-1224

20. Abrous DN, Koehl M, Le Moal M: Adult neurogenesis: from precursors to network and physiology. Physiol Rev 2005, 85:523-569.

21. Lie DC, Dziewczapolski G, Willhoite AR, Kaspar BK, Shults CW, Gage FH: The adult substantia nigra contains progenitor cells with neurogenic potential. J Neurosci 2002, 22:6639-6649.

22. Parent JM: Injury-induced neurogenesis in the adult mammalian brain. Neuroscientist 2003, 9:261-272.

23. Guillemin GJ, Croitoru-Lamoury J, Dormont D, Armati PJ, Brew BJ: Quinolinic acid upregulates chemokine production and chemokine receptor expression in astrocytes. Glia 2003, 41:371-381.

24. Losy J, Zaremba J: Monocyte chemoattractant protein-1 is increased in the cerebrospinal fluid of patients with ischemic stroke. Stroke 2001, 32:2695-2696

25. Fricker RA, Carpenter MK, Winkler C, Greco C, Gates MA, Bjorklund A: Sitespecific migration and neuronal differentiation of human neural progenitor cells after transplantation in the adult rat brain. $J$ Neurosci 1999, 19:5990-6005.

26. Magge SN, Malik SZ, Royo NC, Chen HI, Yu L, Snyder EY, O'Rourke DM, Watson DJ: Role of monocyte chemoattractant protein-1 (MCP-1/CCL2) in migration of neural progenitor cells toward glial tumors. J Neurosci Res 2009, 87:1547-1555.

27. Gage FH: Mammalian neural stem cells. Science 2000, 287:1433-1438.

28. Horner PJ, Gage FH: Regenerating the damaged central nervous system. Nature 2000, 407:963-970.

29. Emsley JG, Mitchell BD, Kempermann G, Macklis JD: Adult neurogenesis and repair of the adult CNS with neural progenitors, precursors, and stem cells. Prog Neurobiol 2005, 75:321-341.

30. Arvidsson A, Collin T, Kirik D, Kokaia Z, Lindvall O: Neuronal replacement from endogenous precursors in the adult brain after stroke. Nat Med 2002, 8:963-970. 
31. Ceradini DJ, Kulkarni AR, Callaghan MJ, Tepper OM, Bastidas N, Kleinman ME, Capla JM, Galiano RD, Levine JP, Gurtner GC: Progenitor cell trafficking is regulated by hypoxic gradients through HIF-1 induction of SDF-1. Nat Med 2004, 10:858-864.

32. Peng H, Sun L, Jia B, Lan X, Zhu B, Wu Y, Zheng J: HIV-1-infected and immune-activated macrophages induce astrocytic differentiation of human cortical neural progenitor cells via the STAT3 pathway. PLoS One 2011, 6:e19439.

33. Karpus WJ, Ransohoff RM: Chemokine regulation of experimental autoimmune encephalomyelitis: Temporal and spatial expression patterns govern disease pathogenesis. J Immunol 1998, 161:2667-2671.

34. Johnstone M, Gearing AJ, Miller KM: A central role for astrocytes in the inflammatory response to beta- amyloid; chemokines, cytokines and reactive oxygen species are produced. J Neuroimmunol 1999, 93:182-193.

35. Minami M, Satoh M: Chemokines as mediators for intercellular communication in the brain. Nippon Yakurigaku Zasshi 2000, 115:193-200

36. Drew TKPD: Cytokines and Brain. In Inflammatory disorders of the nervous system: pathogenesis, immunology, and clinical management. Volume 1. Edited by Alireza Minagar JSA. Totowa, N.J: Humana Press; 2005:41-80.

37. Schwartz L, Major EO: Neural progenitors and HIV-1-associated central nervous system disease in adults and children. Curr HIV Res 2006, 4:319-327.

38. Smits HA, Rijsmus A, van Loon JH, Wat JW, Verhoef J, Boven LA, Nottet HS: Amyloid-beta-induced chemokine production in primary human macrophages and astrocytes. J Neuroimmunol 2002, 127:160-168.

39. Bakhiet M, Mousa A, Seiger A, Andersson J: Constitutive and inflammatory induction of alpha and beta chemokines in human first trimester forebrain astrocytes and neurons. Mol Immunol 2002, 38:921-929.

40. Bajetto A, Bonavia R, Barbero S, Florio T, Schettini G: Chemokines and their receptors in the central nervous system. Front Neuroendocrinol 2001, 22:147-184.

41. Belmadani A, Tran PB, Ren D, Miller RJ: Chemokines regulate the migration of neural progenitors to sites of neuroinflammation. J Neurosci 2006, 26:3182-3191

doi:10.1186/2047-9158-1-15

Cite this article as: Wu et al:: Directed migration of human neural progenitor cells to interleukin- $1 \beta$ is promoted by chemokines stromal cell-derived factor-1 and monocyte chemotactic factor-1 in mouse brains. Translational Neurodegeneration 2012 1:15.

\section{Submit your next manuscript to BioMed Central and take full advantage of:}

- Convenient online submission

- Thorough peer review

- No space constraints or color figure charges

- Immediate publication on acceptance

- Inclusion in PubMed, CAS, Scopus and Google Scholar

- Research which is freely available for redistribution 